\title{
Satellite imagery technology in public health: analysis of site catchment areas for assessment of poliovirus circulation in Nigeria and Niger
}

\author{
Marina Takane, ${ }^{1}$ Shizu Yabe, ${ }^{2}$ Yumiko Tateshita, ${ }^{2}$ Yusuke Kobayashi, ${ }^{3}$ Akihiko Hino, ${ }^{3}$ \\ Kazuo Isono, ${ }^{3}$ Hiromasa Okayasu, ${ }^{1}$ Ousmane M. Diop, ${ }^{1}$ Takeo Tadono \\ ${ }^{1}$ World Health Organization, Geneva, Switzerland; ${ }^{2}$ Japan Aerospace Exploration Agency, \\ Tokyo; ${ }^{3}$ Remote Sensing Technology Center of Japan, Tokyo, Japan
}

\begin{abstract}
Environmental surveillance supplements the surveillance of acute flaccid paralysis by monitoring wastewater for poliovirus circulation. Building on previous work, we analysed wastewater flow to optimise selection and placement of sampling sites with higher digital surface model (DSM) resolution. The newly developed 5-m mesh DSM from the panchromatic, remote-sensing instruments for stereo mapping on-board the Japanese advanced land observing satellite was used to estimate catchment areas and flow of sewage water based on terrain topography. Optimal sampling sites for environmental surveillance were identified to maximise sensitivity to poliovirus circulation. Population data were overlaid to prioritise selection of catchment areas with dense populations. The results for Kano City, Nigeria were compared with an analysis based on existing 30- and 90-m mesh digital elevation model (DEM). Analysis based on 5-m mesh DSM was also conducted for three cities in Niger to prioritise the selection of new sites. The analysis demonstrated the feasibility of using DSMs to
\end{abstract}

Correspondence: Marina Takane, World Health Organization, 20 Appia Avenue, CH-1211 Geneva 27, Switzerland.

Tel: +41.22.7914547 - Fax: +41.22.7914332

E-mail: takanem@who.int

Key words: Environment surveillance; Digital elevation models; Poliovirus; Surface water hydrology; Satellite remote sensing.

Acknowledgments: funding for this study was provided by World Health Organization (WHO), Geneva, Switzerland (PO 201062869) and the Bill and Melinda Gates Foundation, Seattle, WA, USA (0PP50278). The authors thank Dr. Roland Sutter (WHO) for comments that greatly improved the manuscript, Vince Seaman for supporting DEM analysis of ES catchment areas within GPEI, and Dr. Hiroki Nakatani (WHO) for his support of the JAXAWHO collaboration.

Received for publication: 18 February 2016.

Revision received: 29 August 2016.

Accepted for publication: 31 August 2016.

(C) Copyright: M. Takane et al., 2016

Licensee PAGEPress, Italy

Geospatial Health 2016; 11:462

doi:10.4081/gh.2016.462

This article is distributed under the terms of the Creative Commons Attribution Noncommercial License (CC BY-NC 4.0) which permits any noncommercial use, distribution, and reproduction in any medium, provided the original author(s) and source are credited. estimate catchment areas and population size for programme planning and outbreak response with respect to polio. Alternative sampling points in Kano City that would cover a greater population size have been identified and potential sampling sites in Niger are proposed. Comparison with lower-resolution DEMs suggests that the use of a 5-m mesh DSMs would be useful where the terrain is flat or includes small-scale topographic changes not captured by 30 -m data searches.

\section{Introduction}

In 1988, the World Health Assembly (WHA) resolved to eradicate poliomyelitis globally by the year 2000 (WHA, 1988). Since then, the Global Polio Eradication Initiative (GPEI) has made steady progress towards this goal. The South-east Asian region was certified by the World Health Organization (WHO) as polio-free in March 2014 (WHO, 2015b); thus four of WHO's six geographical regions, covering over $80 \%$ of the world's population, are now certified as polio-free. The incidence of poliomyelitis has decreased by more than $99 \%$; from more than 350,000 cases in 1988 to 74 cases in 2015 (GPEI, 2016).

The gold standard for poliomyelitis surveillance is case-based surveillance for acute flaccid paralysis (AFP) cases, which is the sudden onset of weakness and floppiness in any part of the body. Poliomyelitis cases are detected through AFP surveillance for children under 15 years of age, or persons of any age if polio is suspected clinically, by testing stool specimens for the presence of polioviruses. However, most polio infections are asymptomatic and fewer than $1 \%$ of all poliovirus infections cause actual paralytic poliomyelitis (WHO, 2015a) making it difficult to detect imported cases or outbreaks through AFP surveillance before poliovirus circulation becomes widespread. Therefore, the GPEI supplements AFP surveillance with environmental surveillance (ES), in which sewage water is sampled and analysed for the presence of poliovirus to allow early detection of poliovirus circulation. As individuals infected with poliovirus excrete the virus in the faeces for several weeks whether they are symptomatic or not, subjecting sewage samples to screening is considered effective for the detection of poliovirus circulation in a specific area. As most parts of the world are now polio-free, the objective of using ES is to detect the importation and circulation of poliovirus as early as possible so that a timely outbreak response can be conducted in the form of additional immunisation campaigns and strengthened surveillance in target areas. ES has been established in currently or previously poliovirus-infected countries, such as Afghanistan, India, Pakistan and Nigeria, as well as in many polio-free countries that remain at risk of importation, including China, Egypt, Japan and many European countries (Levitt et al., 2014). Previous research indicates that ES has a high sensitivity for the detection of the presence of poliovirus. Hovi et al. 
(2001) flushed poliovirus type 1 (Sabin strain) into the Helsinki sewage network and concluded that it would be possible to detect its circulation from a single sewage sample even if only 1 out of 10,000 inhabitants in the catchment area would be excreting the virus. Similarly, Lodder et al. (2012) provided monovalent (type 1 or type 3 ) oral (i.e. live) poliovirus vaccine (OPV) to 228 subjects in The Netherlands, then monitored its excretion in stools of these subjects at the same time as they collected sewage samples at a pumping station in the area covering a population of 37,000. The results suggest that ES is capable of detecting a few hundred subjects excreting poliovirus among a population of tens of thousands. Based on these findings, the Global Polio Laboratory Network (http://polioeradication.org/polio-today/polio-now/surveillance-indicators/the-global-polio-laboratory-network-gpln/) recommends that the preferred size of the source population be 100,000-300,000 per site (WHO, 2003). In order to maximise the effectiveness of ES, it would be important to identify sampling sites with this source population size that includes high-risk populations. Currently, ES sites are primarily selected based on local knowledge of the location of open sewage canals and water flows without any systematic estimation of catchment area or population. This empirical approach may not identify all potential sampling sites even if it covers high-risk source populations. In this context, the Bill \& Melinda Gates Foundation (BMGF), the Environmental Systems Research Institute (ESRI), and Novel-T (http//www.novel-t.ch/) have analysed the terrain surrounding existing ES sites to estimate the flow of sewage based on digital elevation models (DEMs) in order to identify optimal sampling points, which would maximise the sensitivity to detect the poliovirus circulation (Novel-T, 2016). DEMs represent a digital model of the Earth's surface, derived from remote sensing data using satellites. Currently, 30-m DEMs of the world are publicly available for free (Farr et al., 2007) enabling applications in different fields such as ecology, agriculture, forestry, urban studies and archaeology. In public health, DEMs have been used to assess habitat suitability or other relevant environmental variables (e.g., temperature, rainfall) (Hamm et al., 2015). DEMs can also be used to identify water bodies and areas at risk of flooding (Soti et al., 2010, 2012; Walz et al., 2015).

Building on the success of earlier analyses, WHO, the Japan Aerospace Exploration Agency (JAXA) and the Remote Sensing Technology Center of Japan (RESTEC) have collaborated in a pilot study of higher-resolution DEM. The newly developed 5-m mesh DSM of the panchromatic remotesensing instrument for stereo mapping (PRISM) on-board the advanced land observing satellite (ALOS) provides a height accuracy of $3.3 \mathrm{~m}$ (based on root mean square error), which can be expected to provide better results than previously available. The overall aim of the study was to demonstrate programme feasibility and utility of analysis based on DEMs for the polio eradication programme, including the estimation of catchment area and population in the selection and assessment of ES sites. Specific objectives of the project included the following.

First, application of the analysis to existing sampling sites in Kano City, Nigeria, specifically: comparison of results based on publicly available 90- and 30-m mesh with JAXA's ALOS-generated world three-dimensional topographic map (AW3D) 5-m mesh data to assess the usefulness of using a higher DEM resolution; and comparison of identified sampling points against existing sampling sites to see if the use of DEMs can indeed improve selection of sampling sites.

Second, programmatic application of the method in three cities in Niger to support the selection of new sampling sites.

ALOS was launched by JAXA in January 2006 and photographed 6.5 million scenes around the world in its five years of operation. After exceeding/meeting its designed (three years) and targeted (five years) life, a power generation anomaly causing communication loss occurred in April 2011 leading to the formal termination of the operation of the satellite in May 2011. The Advanced Optical Satellite for the follow-up mission is scheduled to be launched in 2020 .

\section{Materials and Methods}

\section{Satellite imagery used}

There are two types of DEMs: i) the digital surface model (DSM) representing the ground surface with all objects such as plants and buildings; and ii) the digital terrain model (DTM) representing the bare ground surface without any such objects. Currently, $90-\mathrm{m}$ mesh and 30 $\mathrm{m}$ mesh DTM datasets are publicly available from the shuttle radar topography mission (SRTM) data (Farr et al., 2007) from the National Aeronautics and Space Administration (NASA) of the United States. JAXA has produced 5-m mesh and 30-m mesh global DSM datasets using archived AW3D data from PRISM on-board ALOS (Tadono et al., 2014; JAXA, 2015). The 5 -m mesh dataset provides the highest precision global three-dimensional (3D) map with a horizontal accuracy of 5 meters (Takaku et al., 2016). Height accuracies of the 90-m mesh DEM (SRTM), 30-m mesh DSM (ALOS) and 5-m mesh DSM (ALOS) are approximately 7.5, 4.4, and 3.3 m, respectively (Tadono et al., 2016; Takaku et al., 2016). The height provided by the AW3D topography data concerns the top of canopies (height of surface objects including buildings and trees) since it is calculated using images taken from space.

\section{Application in Kano City, Nigeria}

Kano City in Nigeria was selected for the analysis because it is wellknown as a poliovirus reservoir and the sensitivity of ES sites to new importations and outbreaks is critical for the polio eradication programme. ES monthly samples were taken from three sites in Kano City: Kurna Masallachi station, Jakara police station and Gogau Fagge station. Based on the AW3D topographic data of Kano City, we conducted the analysis of the three ES site catchment areas based on the 5-m mesh DSM. Specifically, the steps of the analysis (Figure 1) were as follows.

First, since topographic data are influenced by structures on the

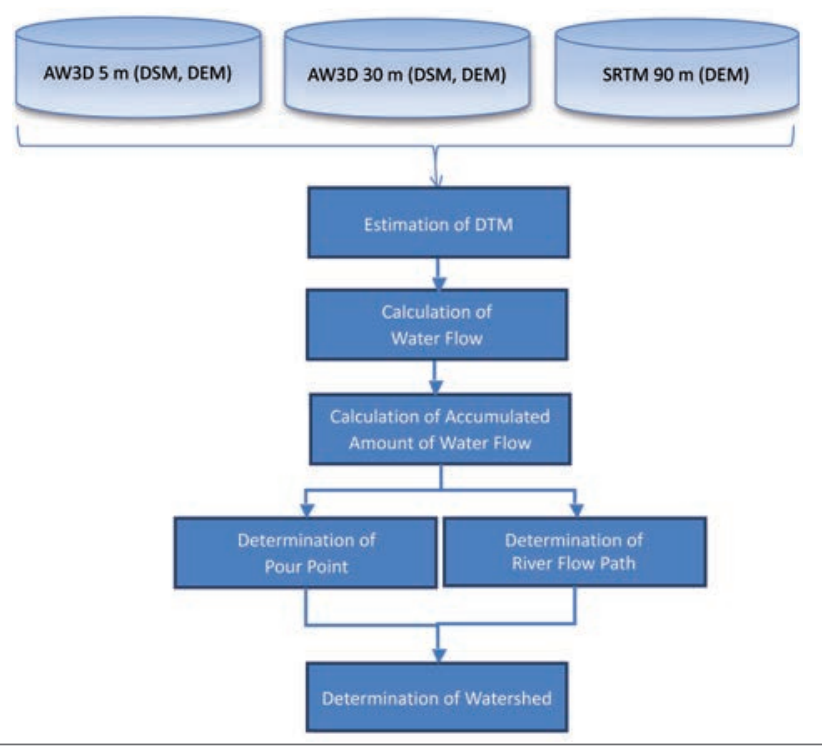

Figure 1. Identification of the catchment areas. AW3D, ALOSgenerated world three-dimensional topographic map; DSM, digital surface model; DEM, digital elevation model. 
ground, a minimisation filter of 25-m radius was applied to AW3D DSM to estimate the DTM, which is needed as the wastewater flow is estimated based on the elevation of the terrain.

Second, slope and water flow direction were computed for the estimated DTM based on the obvious assumption that wastewater flows from an area of higher elevation to lower elevation, an approach only valid in areas with open sewer systems where wastewater flow is based on gravity.

Third, the accumulated amount of water flow was computed based on the number of pixels (5-m mesh) flowing into any given pixel area, a step required to determine the river flow paths in step (5) below.

Four, the pour points, i.e. the lowest elevation spots within the watershed into which the water flows, were determined.

Five, the accumulated water flow computed to be above a certain threshold, imputed to be a river flow path, was determined. These synthetic streams represent the putative flow of wastewater for the purposes of this analysis.

Six, based on the definition of watersheds as the boundary separating adjacent catchment areas, the latter were determined from the pour point and the slope and direction of water flow.

Seven, the resulting catchment areas were overlaid on satellite imagery of the city adding contour lines showing the elevation with the populations within each catchment area, estimated based on the delineation of the area and the corresponding population density in the AfriPop dataset alpha, version 2014 (WorldPop, 2016).

For Kano City, we compared the catchment areas estimated by 5-, 30and 90-m mesh DEMs for the three existing sampling points. We also analysed the catchment areas in the rest of the city to see if more optimal sampling points existed. The sizes were obtained by taking the drainage point closest in distance to the actual sampling point and computing the expanse of each catchment area. Catchment areas for the exact coordinates of the existing sampling points could not be computed as they were not located directly on a drainage line. For example, the existing sampling point (intake point) of Gogau Fagge station did not intersect with a model-generated blue line. In such cases, field visits should be conducted to find out whether there is a real water flow around the existing intake point. Higher-resolution satellite imagery may in future be helpful to establish the actual water flow.

\section{Topographical analyses in Niger}

Given its proximity and population movement to and from Nigeria, Niger remains a high-risk country for poliovirus reintroduction and thus the establishment of ES in Niger represents a high priority for the GPEI. WHO and JAXA/RESTEC analysed the topography of three cities in Niger (Diffa, Maradi and Niamey) at the 5-m mesh level. Using the same method that was applied in Kano City, sewage (river flow) lines, catchment areas and estimated population per catchment area were computed. Potential ES sampling sites were identified and prioritised according to this analysis as a part of a desk review prior to the actual selection of sampling sites based on in-country consultation.

\section{Results}

\section{Kano City, Nigeria}

The results of analysis for Kano City are shown in Figures 2 to 5 . Figure 2 shows the contour lines, existing intake points and estimated drainage points overlaid on satellite imagery. While the interval for the contour lines is $5 \mathrm{~m}$, the height accuracy of the 5 -m mesh DSM is greater $(3.3 \mathrm{~m})$. Figure 3 shows the partition of the city into catchment areas highlighting the catchment areas with existing intake points and drainage points, i.e. those into which the water should flow based on the analysis of the elevation of the terrain. This figure suggests that

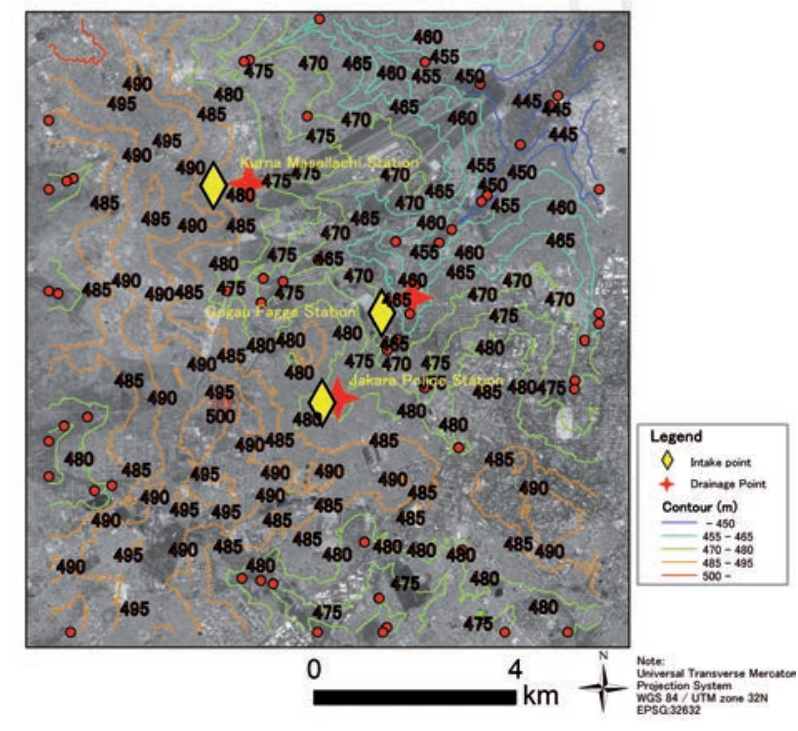

Figure 2. Height contour lines for Kano City, Nigeria estimated from digital elevation model with a $25-\mathrm{m}$ radius minimisation filter. Scattered numbers indicate heights in meters.

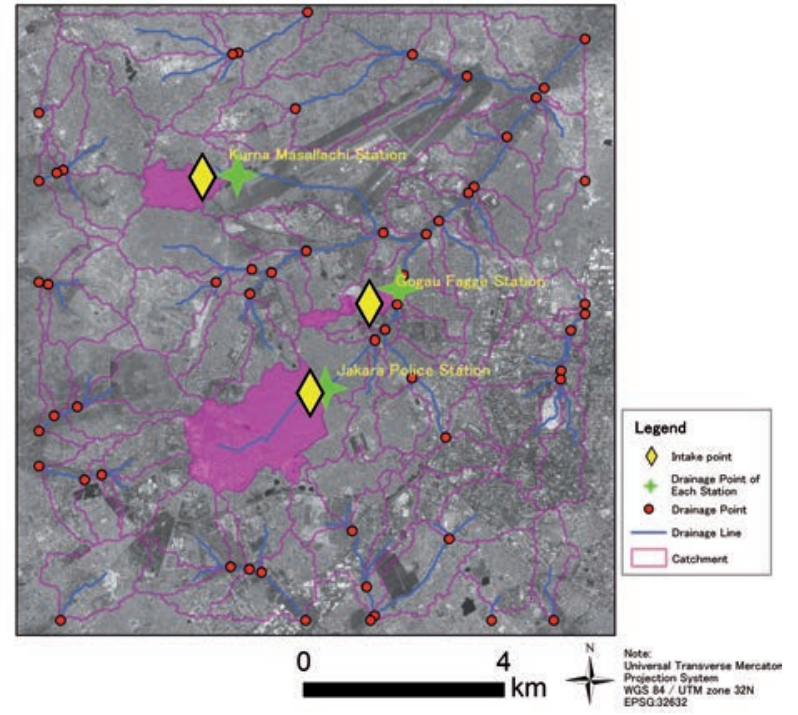

Figure 3. Estimated water flow paths and catchment areas in Kano City, Nigeria. Partition of the city into catchment areas (bounded by purple lines) with the estimated water flows indicated in blue. The yellow diamonds indicate the existing sampling points with their corresponding catchment areas shaded in purple. 
the existing intake points could be optimised by shifting them to the drainage point just downstream of the shaded areas as this would allow collection of wastewater flow from the entire shaded area. A comparison of catchment area size for the actual and the optimal sampling points showed that the catchment area for the optimal sampling point was larger in all three cases, at times by approximately $30 \%$. Feasibility of moving the intake points downstream would require a field visit to assess the suitability of the drainage points as ES sampling sites and to validate the findings of the analysis. Figure 4 shows the population estimates of the optimised catchment areas: the Jakara police station sampling point appears to be covering an area with much higher population compared to the other two sampling sites but within the recommended range of 100,000 to 300,000 population per site.

Figure 5 shows the comparison of catchment areas estimated based on 5-, 30- and 90-m mesh DEM data for the three existing sampling sites. The catchment areas for Jakara police station are quite similar for the three DEMs (Figure 5B). For Kurna Masallachi station, the 5and 30-m mesh results are similar, while the $90-\mathrm{m}$ SRTM gives a much larger catchment area (Figure 5C). The results for Gogau Fagge station (Figure 5A) are the most disparate with regard to the 5-m mesh and 30/90-m mesh results.

\section{Three cities in Niger}

Figure 6 shows the catchment areas, computed river flow paths (sewage lines) and population estimates in Diffa, Maradi and Niamey. Based on visual inspection of the satellite imagery, the sewage lines are generally consistent with the major rivers in the area. For Maradi and Niamey, the topography and population density are such that the selection and prioritisation of sampling sites is fairly obvious: the wastewater is expected to flow into the major rivers from the higher elevation areas of the city and the most densely populated areas are quite concentrated. Diffa has a more spread-out population and the terrain is very flat.

In September 2014, twelve candidate sampling points in these three cities were selected based on the analysis. Final selection of sampling points would be based on: i) accessibility of sampling points (e.g. open sewage, rivers); ii) appropriateness of the sample (e.g. absence of sewage treatment plants, waste from factories, etc.); and iii) adequateness of flow (e.g. presence of water flow to enable sample collection).

\section{Discussion}

This project assessed the feasibility and utility of the AW3D 5-m mesh DSM data in selecting poliovirus ES sites to the polio eradication programme. The comparison of estimated catchment areas with 90-, 30-, and 5-m mesh DEM data in Kano, Nigeria showed that a high resolution (i.e. 5-m mesh) was especially useful in places with very flat topography or rapidly changing terrain which are not captured by lower resolution DEMs. Areas with spread-out population such as in Diffa, Niger also benefitted from this analysis by simply overlaying the population density to identify high-priority areas. As part of the polio endgame strategy, WHO is currently expanding environmental surveillance in approximately 10 countries by the end of 2016 (WHO, 2014). As demonstrated in our analysis in Nigeria and Niger, the analysis with DEM data enables the rationalisation of the selection of sampling points in high-risk areas, including the estimation of catchment areas and populations, which is not possible when using only empirical methods.In particular, the AW3D 5 mesh DSM data can provide additional value especially in areas requiring higher resolution data to obtain reli- able results.

With respect to the Nigeria data, it is likely that the 5-m mesh DSM would be able to capture the effect of local changes in the elevation to the north and south of the Gogau Fagge sampling site in determining the catchment area. Thus, use of a higher resolution DEM seems most useful when analysing an area with rapid terrain changes with regard to height; for example, terrains with many local hills. In areas, in which the change in elevation is regular and reasonably steep, lower-resolution DEMs of 30- or $90-\mathrm{m}$ are likely to provide similar results to the 5m-mesh DSM. Further, an environmental surveillance review for Nigeria that took place in September 2014 assessed the placement of the existing sites, and identified additional potential ES sites. The present analysis was a key support for the review of the Kano City area, particularly in the selection of new sites. Two new sites selected in the southern and eastern parts of the city to cover populations in areas outside the catchment of the existing sites have been operational since November 2014 and will provide additional information in due course.

Comparison of the sampling sites estimated in DEM analysis and the actual sampling sites in Kano, Nigeria indicate that the analysis with DEM data may be capable of suggesting better sites covering areas and populations of higher priority. This suggests that the DEM analysis can be applied to all existing ES sites (e.g., Afghanistan, India, Nigeria, Pakistan). Currently, BMGF has contracted Novel-T to conduct this analysis for all sites with the freely available 30 -m mesh DEM (Novel$\mathrm{T}, 2016$ ). In addition, this analysis provided a measure of rationalisation in the interpretation of the ES results, including estimation of the population size covered. To date, a positive ES sample can only be interpreted as the presence of a poliovirus excretor somewhere upstream in the vicinity of the sampling site. However, the analysis facilitates the localisation of the probable excretor in question as the search can be narrowed down to the catchment area and the population of the sampling site providing a more rational approach to planning the extent of mop-up polio vaccination campaigns and assessing risk of further circulation subsequent to a positive environmental sample. Negative results are more difficult to interpret because negative samples may indicate the absence of circulating polio viruses or be due to a range of

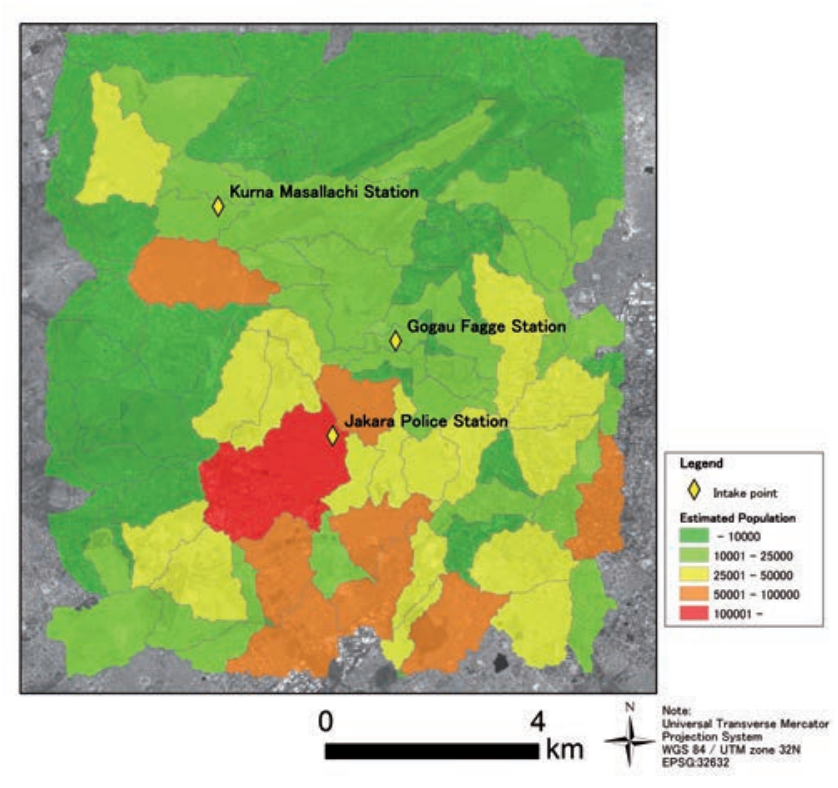

Figure 4. Population estimates for catchment areas in Kano City, Nigeria. 
other reasons, such as a poorly or improperly selected collection sites, inadequate or inappropriate sample collection methods, inadequate sample transport or storage, inadequate laboratory methods or inappropriate approaches in general.

One limitation of this analysis is that AW3D is generated from data collected between January 2006 and April 2011 - the time period when ALOS was in operation. Therefore, the results of this analysis do not include land cover information after April 2011. Also, the application of the analysis is limited to locations where the wastewater flow is based on open sewer systems and gravity. Extensive use of other sanitation systems (e.g. pit latrines or piped sewage systems using pumps) is likely to skew the results as well. Other factors, such as presence of industrial waste, high temperatures and sunlight must also be taken into consideration. Therefore, it is important to validate the results through field visits so that potential sites can be assessed for sample collection suitability.

Closing this discussion, the inherent level of uncertainty in the results of the analysis must be admitted: interpolation between data

A

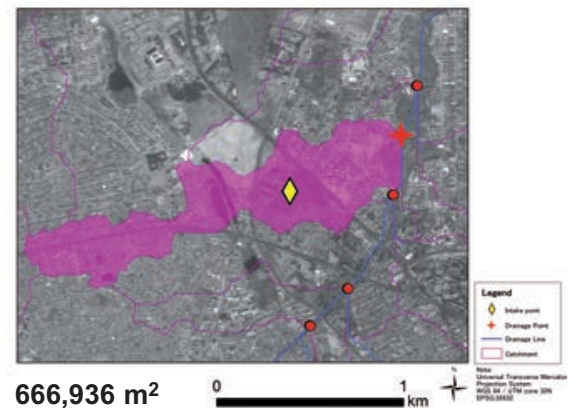

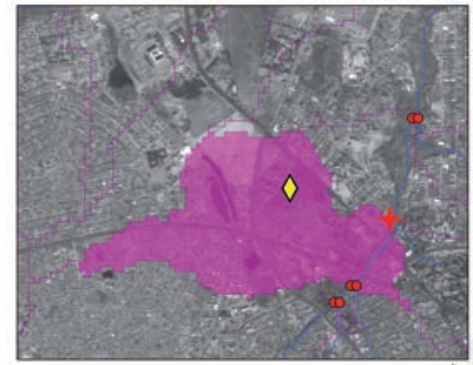

$892,800 \mathrm{~m}^{2}$

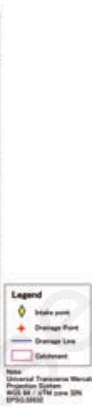

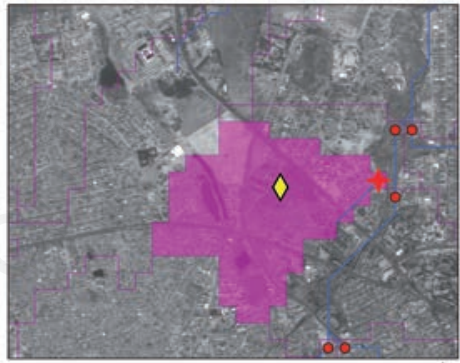

$737,100 \mathrm{~m}^{2}$

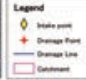

$+5$

B

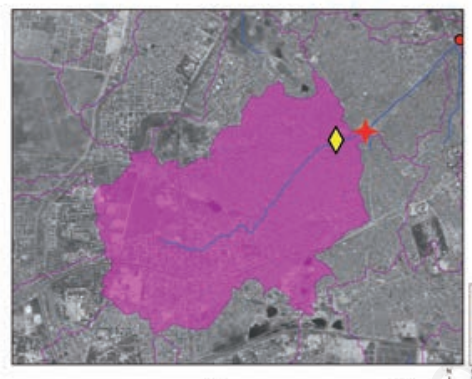

$4,734,874 \mathrm{~m}^{2}$

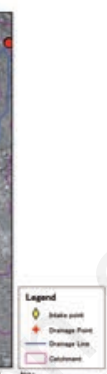

+ 봄=․․

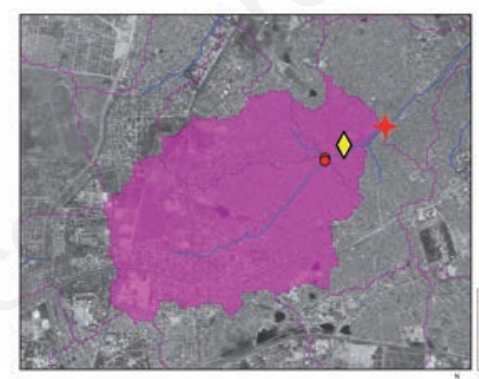

$4,705,200 \mathrm{~m}^{2}$

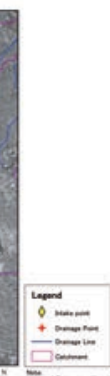

$2+=$

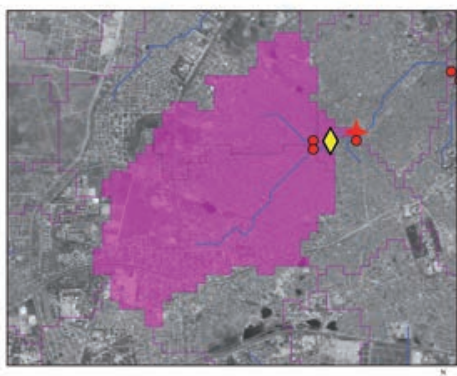

$4,568,400 \mathrm{~m}^{2}$ 。

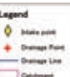

$+5=$

C
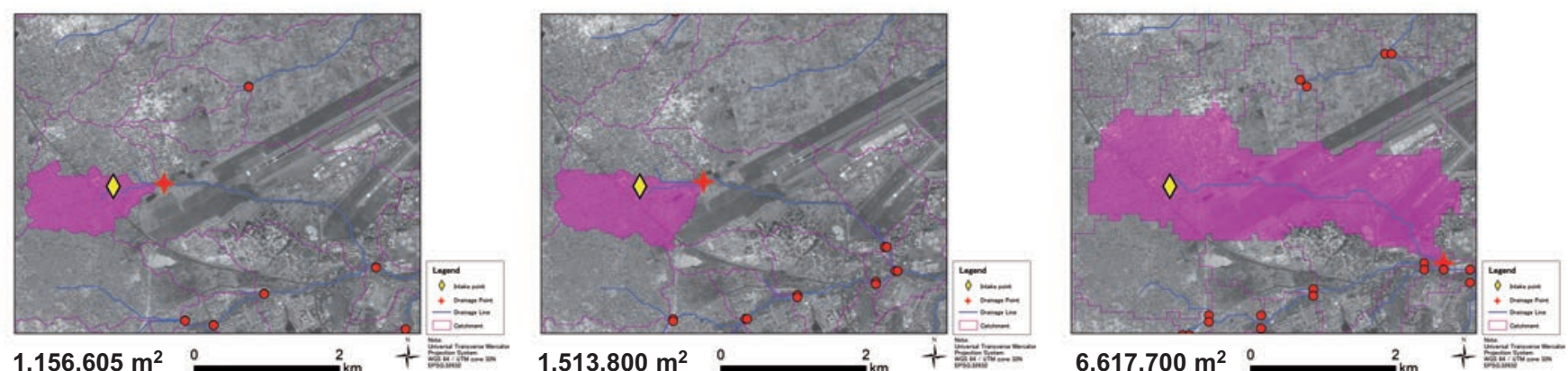

$6,617,700 \mathrm{~m}^{2}$

Figure 5. Comparison of catchment areas based on 5- (left panels), 30- (central panels), and 90-m (right panels) mesh digital elevation model data for the three existing sampling sites. A) Gogau Fagge station; B) Jakara police station; C) Kurna Masallachi station. Numbers under each panel represent catchment areas. 
points in the elevation data may result in error, and the 25-m smoothing filter used to obtain the DTM from the DSM may not be appropriate in all situations. Another possible limitation of using the AW3D dataset DSM is that this type of analysis cannot be applied in all parts of the world at all times, for example areas commonly covered by extensive clouds would preclude this approach. In addition, inclusion of Monte Carlo simulation to obtain confidence intervals would provide a meas-

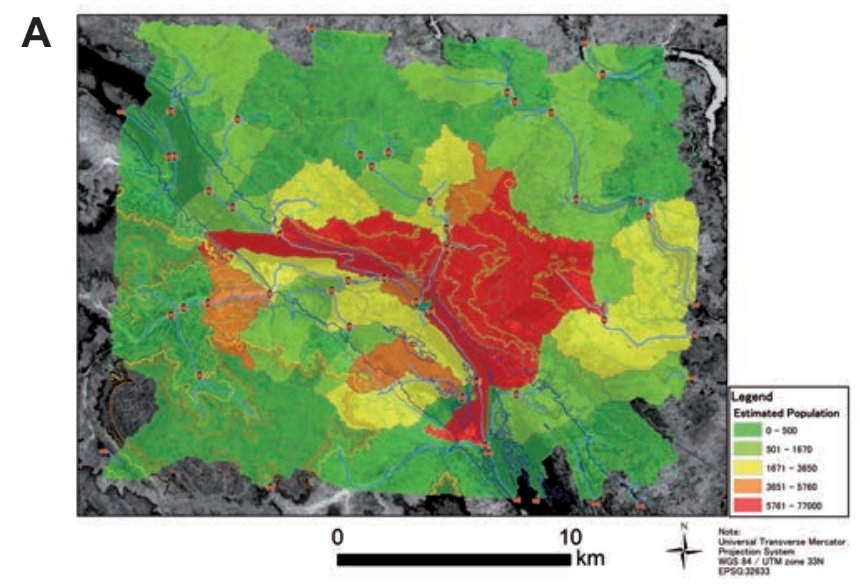

B

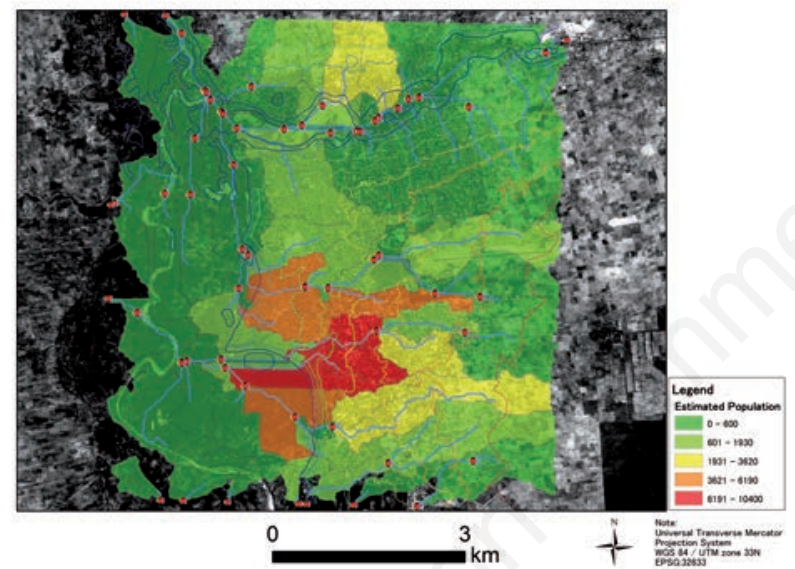

C

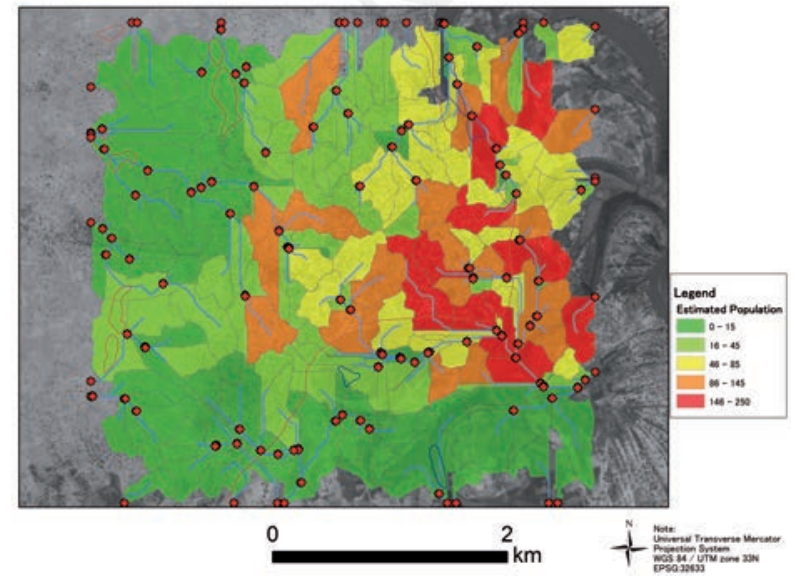

Figure 6. Catchment areas, estimated water flow paths, and population estimates for Niamey (A), Maradi (B), and Diffa (C), Niger. ure of the robustness of the analysis results.

Finally, this project suggests that other diseases that can be monitored through environmental surveillance, as well as programmes involved in wastewater management are also likely to benefit from similar analyses.

\section{Conclusions}

The estimation of catchment areas and population covered by environmental surveillance based on newly developed 5-m mesh global DSMs and population data is a useful tool for the validation and optimisation of existing sites and prioritisation of the selection of new sites. This analysis allows the GPEI to identify the areas that are potentially the source of virus excretion (catchment area), in case of a positive sample, as well as to optimise the placement of new sites to cover highrisk areas and populations.

\section{References}

Farr TG, Rosen PA, Caro E, Crippen R, Duren R, Hensley S, Kobrick M, Paller M, Rodriguez E, Roth L, 2007. The shuttle radar topography mission. Rev Geophys 45:RG2004.

GPEI, 2016. Data and monitoring: polio this week, 2016. Available from: http://www.polioeradication.org/Dataandmonitoring/Poliothisweek .aspx

Hamm NAS, Soares Magalhães RJ, Clements ACA, 2015. Earth observation, spatial data quality, and neglected tropical diseases. PLOS Negl Trop Dis 9:e0004164.

Hovi T, Stenvik M, Partanen H, Kangas A, 2001. Poliovirus surveillance by examining sewage specimens. Quantitative recovery of virus after introduction into sewerage at remote upstream location. Epidemiol Infect 127:101-6.

JAXA, 2015. Precise global digital 3D map 'ALOS World 3D'. Available from: http://www.eorc.jaxa.jp/ALOS/en/aw3d/index_e.htm

Levitt A, Diop OM, Tangermann RH, Paladin F, Kamgang JP, Burns CC, Chenoweth PJ, Goel A, Steven GF, Wassilak SGF, Centers for Disease Control and Prevention, 2014. Surveillance systems to track progress toward global polio eradication worldwide, 20122013. MMWR Morb Mortal Wkly Rep 63:356-61.

Lodder WJ, Buisman AM, Rutjes SA, Heijne JC, Teunis PF, de Roda Husman AM, 2012. Feasibility of quantitative environmental surveillance in poliovirus eradication strategies. Appl Environ Microb 78:3800-5.

Novel-T, 2016. Environmental surveillance: supporting polio eradication. Available from: http://maps.novel-t.ch/\#/catalog/all

Soti V, Puech C, Lo Seen D, Bertran A, Vignolles C, Mondet B, Dessay N, Tran A, 2010. The potential for remote sensing and hydrologic modelling to assess the spatio-temporal dynamics of ponds in the Ferlo region (Senegal). Hydrol Earth Syst Sc 14:1449-64.

Soti V, Tran A, Degenne P, Chevalier V, Lo Seen D, Thiongane Y, Diallo M, Guégan J-F, Fontenille D, 2012. Combining hydrology and mosquito population models to identify the drivers of rift valley fever emergence in semi-arid regions of West Africa. PLOS Negl Trop Dis 6:e1795.

Tadono T, Ishida H, Oda F, Naito S, Minakawa K, Iwamoto H, 2014. Precise global DEM generation by ALOS PRISM. ISPRS Ann Photogramm Remote Sens Spatial Inf Sci 4:71-6. 
Tadono T, H Nagai, H Ishida, F Oda, S Naito, K Minakawa, H Iwamoto, 2016. Generation of the $30 \mathrm{M}$-mesh global digital surface model by ALOS PRISM. ISPRS Ann Photogramm Remote Sens Spatial Inf Sci 41:157-62.

Takaku J, Tadono T, Tsutsui K, Ichikawa M, 2016. Validation of 'AW3D' global DSM generated from ALOS PRISM. ISPRS Ann Photogramm Remote Sens Spatial Inf Sci 2:25-31.

Walz Y, Martin Wegmann M, Stefan Dech S, Giovanna Raso G, Jürg Utzinger J, 2015. Risk profiling of schistosomiasis using remote sensing: approaches, challenges and outlook. Parasite Vector 8:163.

WHA, 1988. WHA41.28 Global eradication of poliomyelitis by the year 2000. World Health Assembly, Geneva, Switzerland. Available from: http://www.who.int/ihr/polioresolution4128en.pdf

WHO, 2003. Guidelines for environmental surveillance of poliovirus cir- culation. World Health Organization, Geneva, Switzerland. Available from: http://apps.who.int/iris/bitstream/10665/67854/1/ WHO_V-B_03.03_eng.pdf

WHO, 2014. Major decisions for OPV2 withdrawal: report from the polio working group. World Health Organization, Geneva, Switzerland. Available from: http:/www.who.int/immunization/sage/meetings/ 2014/october/2_Figueroa_report_from_SAGE_WG_v7.pdf

WHO, 2015a. Poliomyelitis. World Health Organization, Geneva, Switzerland. Available from: http://www.who.int/biologicals/areas/v accines/poliomyelitis/en/

WHO, 2015b. WHO South-East Asia Region certified polio-free. Available from: http://www.searo.who.int/mediacentre/releases/ 2014/pr1569/en/

WorldPop, 2016. Available from: http://www.worldpop.org.uk/ 